\title{
Transmission dynamics and control of Ebola virus disease outbreak in Nigeria, July to September 2014
}

F 0 Fasina (daydupe2003@yahoo.co.uk)1, A Shittu², D Lazarus³, 0 Tomori4, L Simonsen ${ }^{5,6}$, C Viboud ${ }^{6}$, G Chowell ${ }^{6,7}$

1. Department of Production Animal Studies, University of Pretoria, South Africa

2. Department of Theriogenology and Animal Production, Faculty of Veterinary Medicine, Usmanu Danfodiyo University, Sokoto, Nigeria

3. Viral Research Division, National Veterinary Research Institute, Vom, Plateau State, Nigeria

4. Nigerian Academy of Science, University of Lagos Campus, Akoka, Lagos, Nigeria

5. Department of Global Health, Milken Institute School of Public Health, George Washington University, Washington DC, United States

6. Division of International Epidemiology and Population Studies, Fogarty International Center, National Institutes of Health, Bethesda, Maryland, United States

7. School of Human Evolution and Social Change, College of Liberal Arts and Sciences, Arizona State University, Tempe, Arizona, United States

Fasina FO, Shittu A, Lazarus D, Tomori O, Simonsen L, Viboud C, Chowell G. Transmission dynamics and control of Ebola virus disease outbreak in Nigeria, July to September 2014. Euro Surveill. 2014;19(40):pii=20920. Available online: http://www.eurosurveillance.org/ViewArticle.aspx?Articleld=20920

Article submitted on 23 September 2014 / published on og October 2014

We analyse up-to-date epidemiological data of the Ebola virus disease outbreak in Nigeria as of 1 October 2014 in order to estimate the case fatality rate, the proportion of healthcare workers infected and the transmission tree. We also model the impact of control interventions on the size of the epidemic. Results indicate that Nigeria's quick and forceful implementation of control interventions was determinant in controlling the outbreak rapidly and avoiding a far worse scenario in this country.

\section{Outbreak details}

The largest Ebola virus disease (EVD) outbreak to date is ongoing in West Africa, particularly in Guinea, Sierra Leone and Liberia, with a total of 7,178 reported cases including 3,338 deaths as of 1 October 2014 [1]. A total of 20 EVD cases (19 laboratory confirmed, one probable) have been reported in Nigeria, with no new cases reported since 5 September 2014. All 20 cases stemmed from a single importation from a traveller returning from Liberia on 20 July 2014 [2]. The Nigerian index case had visited and cared for a sibling in Liberia who died from the disease on 8 July 2014 [2,3]. Despite being aware of his exposure to Ebolavirus in Liberia, the index case flew from Liberia to Lagos, Nigeria, on a commercial airplane on 20 July 2014 , with a stopover in Lomé, Togo. The case became symptomatic while flying and collapsed at Lagos airport upon landing, which prompted him to seek medical attention and led to a number people being exposed to Ebolavirus. Epidemiological investigation revealed that the index case had contracted Ebolavirus in Liberia; the patient died on 25 July 2014 [4].
A total of 894 contacts were subsequently linked to this index case, including the primary, secondary and tertiary contacts [2].** Importantly, one of the primary contacts of the index case had travelled to Port Harcourt, the capital of Rivers State, at the end of July 2014 and was cared for by a healthcare professional who subsequently became infected and died on 22 August 2014. This deceased healthcare worker was in turn linked to a total of 526 contacts in Port Harcourt [2]. As of 1 October 2014, all contacts had completed the 21-day surveillance follow-up, including those under surveillance in Rivers State, with no new report of incident cases [2]. The World Health Organization is soon to officially declare Nigeria free of active Ebolavirus transmission [2].

Here we assess the epidemiological data for the EVD outbreak in Nigeria from 20 July to 1 October 2014, and use a dynamic disease transmission model to illustrate the effect of forceful interventions in rapidly containing the EVD outbreak in Nigeria. The interventions included timely implementation of careful contact tracing and effective isolation of infectious individuals.

\section{Data sources}

We used up-to-date epidemiological data for the EVD outbreak in Nigeria available from public sources as of 1 October 2014 [1,5-32].

The 19 laboratory-confirmed cases were diagnosed by reverse transcription (RT)-PCR at Lagos University Teaching Hospital and Redeemer University in Lagos. Probable cases are suspected cases evaluated by a clinician or any deceased suspected case with an epidemiological link with a confirmed EVD case $[1,2]$. 
Cumulative reported cases and deaths of Ebola virus disease in Nigeria, July-September 2014*,**

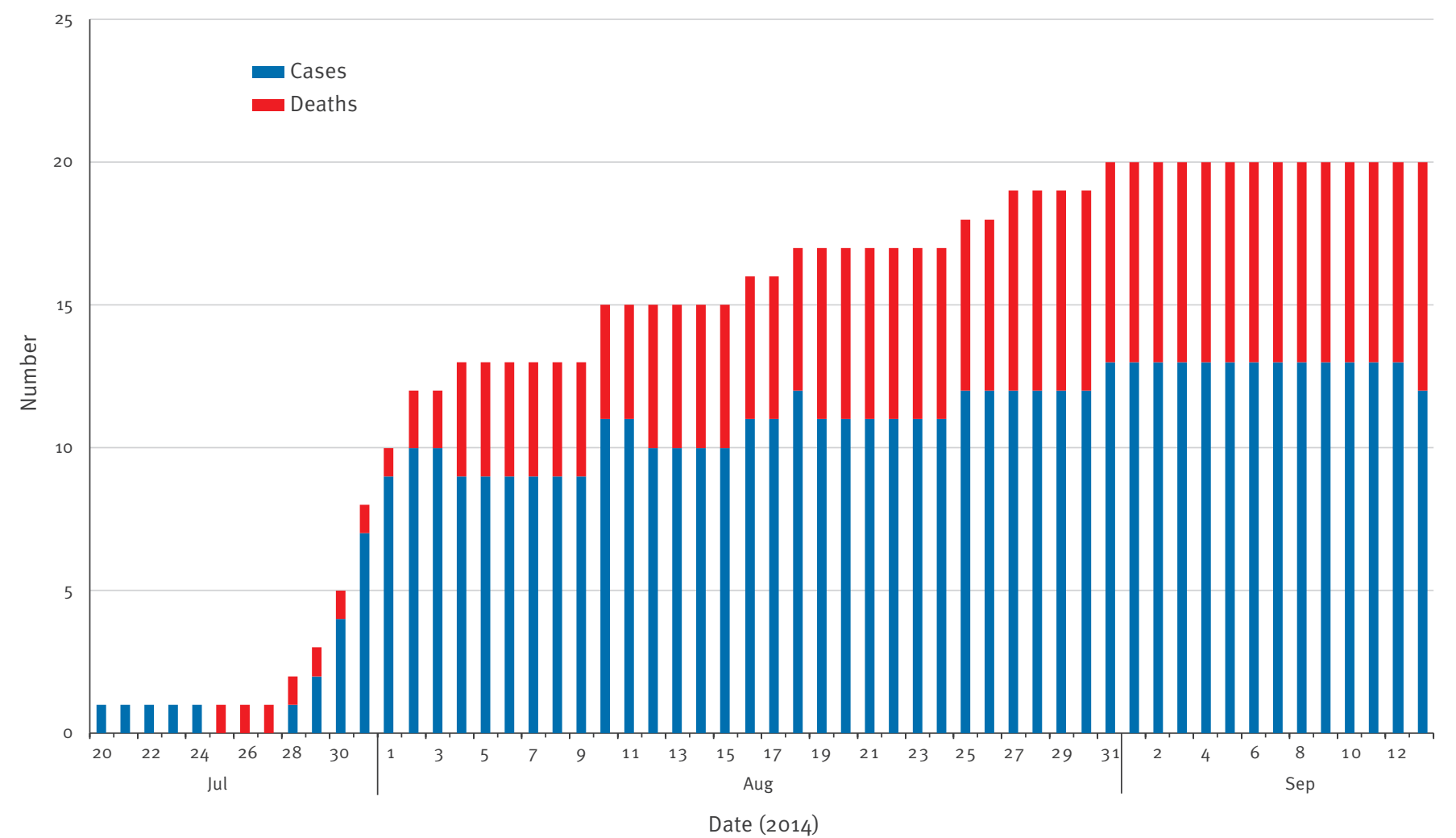

A total of 19 laboratory-confirmed cases, one probable case and eight deaths among the cases have been reported as of 1 October 2014 . The index case entered Nigeria on 20 July 2014 and the onset of outbreak is taken from that date.

To build the Ebola virus disease epidemic curve, we reviewed all relevant information published in Morbidity and Mortality Weekly Report [2] and World Health Organization Ebola situational reports and updates for Nigeria published during July to September 2014 [1,5-31] and categorised the 20 reported Ebola virus disease patients by reporting date and discharge status (dead/alive).

The diagnosis of the index case took approximately three days, while results of the tests for the other confirmed cases were typically available within 24 hours. Samples were also sent to the World Health Organization Reference Laboratory in Dakar, Senegal, for confirmation.

All symptomatic contacts were initially held in an isolation ward. Following laboratory confirmation of EVD, all positive symptomatic contacts were immediately moved to an EVD treatment centre. Asymptomatic suspected contacts were separated from symptomatic contacts. Negative asymptomatic individuals were discharged immediately [2].

\section{Modelling Ebolavirus transmission and control}

We estimated the case fatality rate (number of reported deaths/number of reported cases), the proportion of infected healthcare workers, and the mean number of secondary cases by generation of the disease by analysing a transmission tree. We employed two compartments to differentiate between infectious individuals who were in the community and those who had been identified and placed in isolation in hospital. Using epidemic modelling, we also projected the size of the outbreak in Nigeria if control interventions had been implemented at different dates, and hence estimate how many cases were prevented by early start of interventions.

We carried out stochastic EVD outbreak simulations based on a simplified version of the model proposed by Legrand et al. [33], which was developed to classify the contribution of community, funeral and healthcare settings to the total force of infection. Although the model also accounts for transmission stemming from burial practices that involve touching the body of the deceased, this feature is believed to have less influence on transmission in the EVD outbreak in Nigeria [34]. For the sake of simplicity, we only classified transmission in the community and in healthcare settings by adjusting baseline transmission rates, diagnostic rates and enhancement of infection-control measures (e.g. 


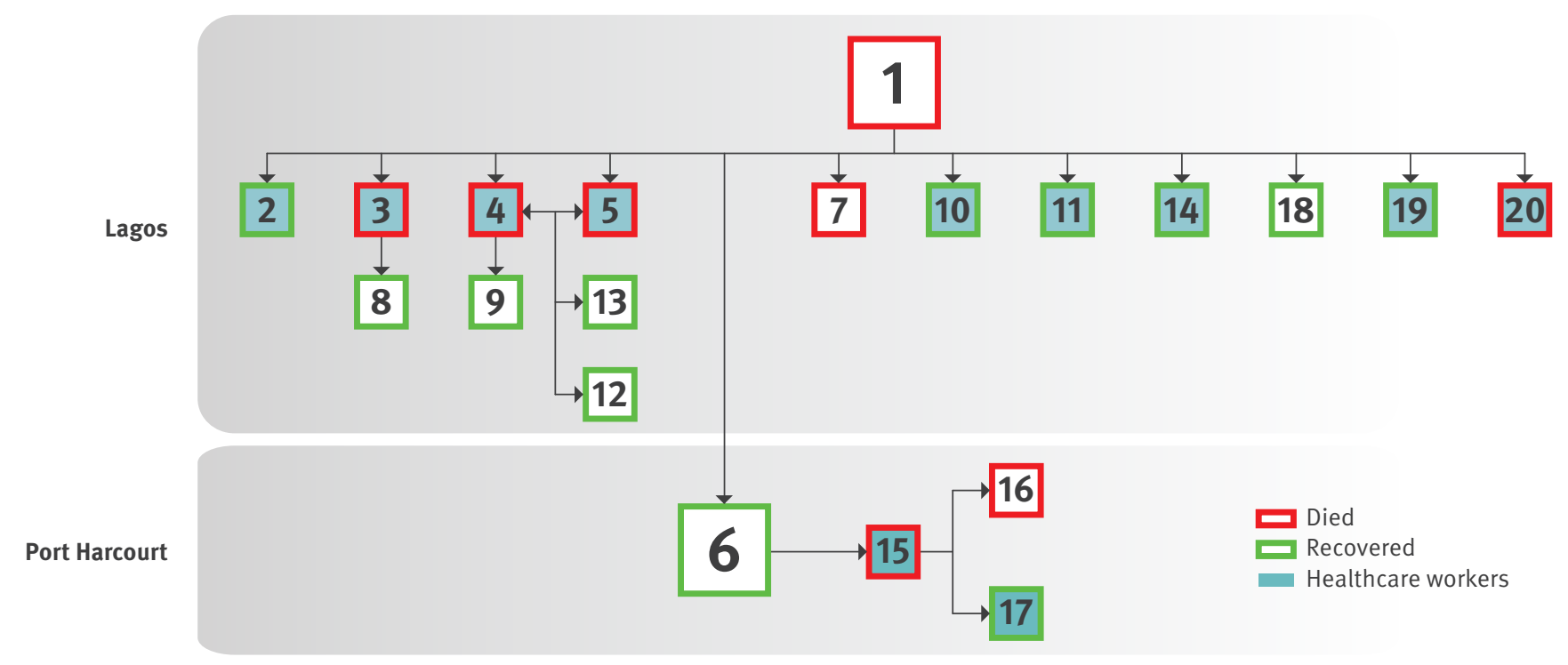

To develop a detailed transmission tree for the patients included in Figure 1, we built on a published tree [2], cross-referencing the information in the tree with that in World Health Organization reports [1,5-31], as well as information from local newspaper reports (e.g. [32]) that provided details on individual patient's infection links and their occupation. We categorised each patient according to the transmission setting (Ebolavirus acquired in a healthcare setting or the community), patient's geographical location (Lagos or Port Harcourt) and discharge status (dead/alive).

strict use of protective equipment by healthcare workers and effective isolation of infectious individuals).

The modelled population was divided into five categories: susceptible individuals (S); exposed individuals (E); Infectious and symptomatic individuals (I); hospitalised individuals $(H)$; and individuals removed from isolation after recovery or disease-induced death $(P)$. Susceptible individuals infected through contact with infectious individuals (secondary cases) enter the latent period at mean rate $\beta(t)(I+l(t) H) / N(t)$ where $\beta(t)$ is the mean human-to-human transmission rate per day, $l(t)$ quantifies the mean relative transmissibility of hospitalised patients compared with that in symptomatic patients in the community, and $\mathrm{N}(\mathrm{t})$ is the total population size at time t. Thus, values of this parameter between 0 and 1 measure the effectiveness of the isolation of infectious individuals that decrease Ebolavirus transmission probability below that seen in the community. Values close to o illustrate "nearperfect' isolation, while values closer to 1 illustrate 'imperfect' isolation strategies. Symptomatic infectious individuals / are hospitalised at a time-dependent mean rate $\gamma_{\mathrm{a}}(t)$ or else recover without being hospitalised, at the mean rate $\gamma_{1}$. Individuals in the 'removed' category do not contribute to the transmission process. For simplicity, it can be assumed that the time-dependent transmission rate $\beta(t)$, the mean relative transmissibility of hospitalised patients $l(t)$, and the mean diagnostic rate $\gamma_{\mathrm{a}}(t)$, remain constant with values at $\beta_{0}$, $l_{0}$, and $\gamma_{\text {ao }}$ before the implementation of intervention measures. Once control interventions are instituted at time $\tau$, the transmission rate decreases to $\beta_{1}\left(\beta_{1}<\beta_{0}\right)$, the mean relative transmissibility of hospitalised patients decreases to $l_{1}\left(l_{1}<l_{0}\right)$ by enhancing infection control measures in healthcare settings, while the diagnostic rate increases to $\gamma_{\mathrm{a} 1}\left(\gamma_{\mathrm{ao}}<\gamma_{\mathrm{a} 1}\right)$ through contact tracing activities.

We carried out stochastic simulations of this transmission model to project the size of the outbreak in Nigeria if interventions (index case identification, contact tracing and isolation of those infected) had been started at different dates (range of 3 to 50 days after the index case arrived in Nigeria), and hence estimate how many cases were prevented by an early start of interventions. Baseline epidemiological parameters were set according to the epidemiology of EVD (i.e. incubation period of 6-12 days [35,36], infectious period of $5-7$ days [37,38], case fatality rate: $35-50 \%$ [36]). Moreover, the mean time from symptom onset to diagnosis $\left(\gamma_{\mathrm{ao}}\right)$ was set at five days before the implementation of interventions [11]. Without loss of generality, we set the effective population size at 10,000,000 (assuming larger population sizes, for example, did not affect our conclusions). $R_{o}$ (the basic reproduction number) denotes the transmission potential before the start of interventions in a completely susceptible population [39], while we refer to $R$, the reproduction number, when transmission is affected by control interventions. We varied $R_{0}$ in the range $1.5-2.0$ before the start of interventions, based on estimates from other affected countries [40-43]. $R_{0}$ 


\section{FIGURE 3}

Simulation results from calibrating the transmission model to assess the timing of control interventions on the size of the Ebola virus disease outbreak in Nigeria
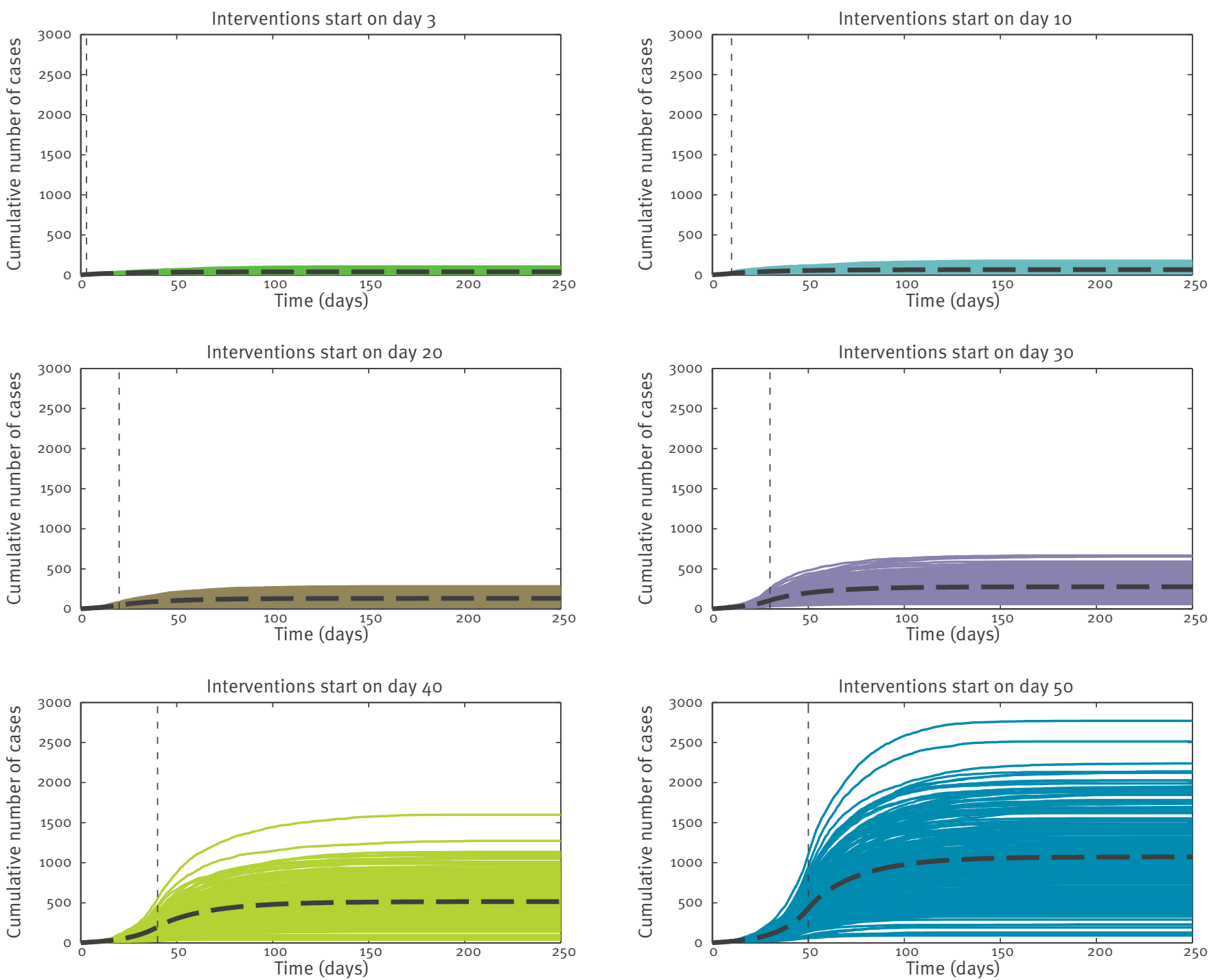

I: mean relative transmissibility of hospitalised patients; $\mathrm{R}_{\mathrm{o}}$ : basic reproduction number.

Baseline epidemiological parameters were set according to the epidemiology of Ebola virus disease and $R_{0}=2$ before the start of interventions. Moreover, the mean time from symptom onset to diagnosis $\left(1 / \gamma_{\text {ao }}\right)$ was set at five days before the implementation of interventions, and the effective population size was set at 10,000,000. After the start of interventions, the mean time from onset to diagnosis was reduced from five days to one day, and the relative infectiousness of hospitalised individuals was reduced by $80 \%$ (i.e. $l=1, l=0.2$ ) to reflect the strict enhancement in infection control measures in hospital settings. Day o corresponds to the day when the index câse was introduced in the population. We analysed 200 stochastic model simulations.

was set by adjusting the baseline transmission rate. After the start of the interventions, only two parameters were adjusted: (i) the mean time from symptom onset to diagnosis was reduced from five days to one day; and (ii) the infectiousness of hospitalised individuals was reduced by $80 \%$ to reflect the tightening of infection control measures in hospital settings relative to levels before the identification of the index case (i.e. $l_{0}=1, l_{1}=0.2$ ).

We ran 200 stochastic simulations starting with the introduction of an index case and 12 local individuals exposed by the index case at the start of the outbreak (i.e. $I(0)=1, E(0)=12)$. We set the timing of start of interventions $\tau$ at day 3 of the simulated outbreak (in line with the Nigerian outbreak response), as well as 10, 20, 30,40 and 50 days, and compared the predicted final epidemic size with that of the outbreak in Nigeria (i.e. 20 EVD cases (laboratory-confirmed and probable)). Simulation code in Matlab is available upon request from the authors.

\section{Results}

Eight of the 20 reported EVD cases reported in Nigeria have died, giving an estimated case fatality rate of $40 \%(95 \% \mathrm{Cl}: 22-61)$ (Figure 1$)$. Of the 20 cases, 11 
Effects of the effectiveness of isolation of infectious individuals on the reproduction number for three values of the diagnostic rate, Ebola virus disease outbreak, Nigeria

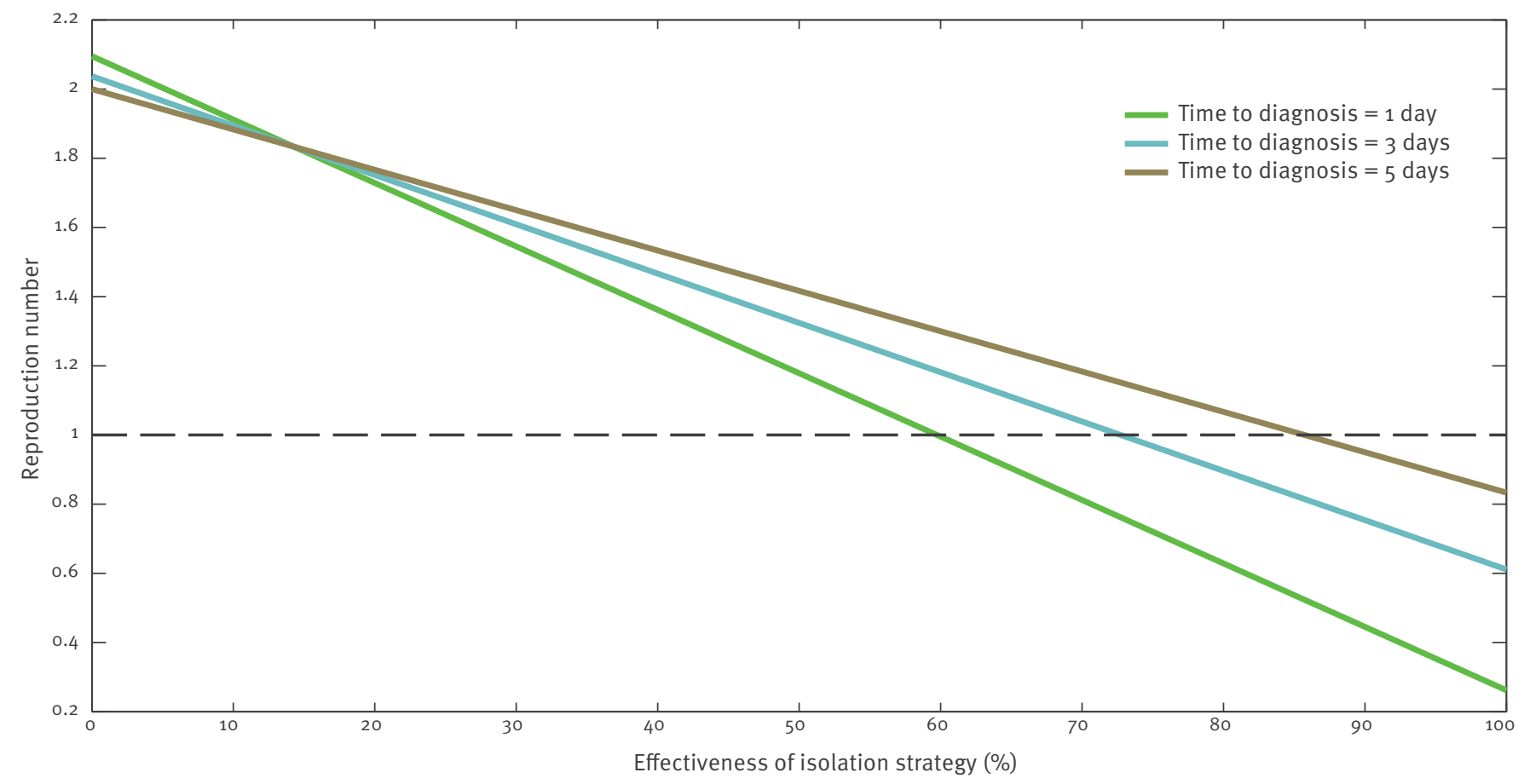

I: mean relative transmissibility of hospitalised patients; R: reproduction number.

There is a critical level of isolation effectiveness of infectious individuals estimated at about $60 \%$ with a mean time from symptoms onset to diagnosis of one day, which is necessary to reduce the reproduction number below the epidemic threshold at $\mathrm{R}=1.0$ and halt the spread of Ebola virus disease.

The baseline $R_{0}$ was set at 2.0 with $l_{0}=1$ and the mean time from symptom onset to diagnosis $\left(1 / \gamma_{\text {ao }}\right)$ was five days before the implementation of interventions.

were healthcare workers; nine of whom acquired the virus from the index case before the disease was identified in the country [1].

We built the transmission tree of the EVD outbreak, which provides information on the history of each case (Figure 2). The index case generated 12 secondary cases in the first generation of the disease. Five secondary cases were generated in the second generation and two secondary cases in the third generation. This leads to a rough empirical estimate of the reproduction number according to disease generation decreasing from 12 during the first generation, to approximately 0.4 during the second and third disease generations.

The projected effect of control interventions on the transmission of Ebolavirus in Nigeria is illustrated in Figure 3.

The effect of the effectiveness of isolation of infectious individuals on the reproduction number is shown in Figure 4 for three values of the diagnostic rate. There is a critical level of isolation effectiveness of infectious individuals estimated at about $60 \%$ with a mean time from symptom onset to diagnosis of one day, which is necessary to reduce the reproduction number below the epidemic threshold at $R=1.0$ and halt the spread of EVD (Figure 4).

\section{Discussion}

We have analysed epidemiological data of what appears to be a limited outbreak of EVD in Nigeria based on data available as of 1 October 2014, with no new EVD cases reported since 5 September 2014. The swift control of the outbreak was likely facilitated by the early detection of the index entering Nigeria from a country where disease is widespread, in combination with intense contact tracing efforts of all contacts of this index case and the subsequent isolation of infected secondary cases [2]. In contrast, the initial outbreak in Guinea remained undetected for several weeks [44]. This detection delay facilitated the transnational spread of the virus to Sierra Leone and Liberia, while difficulties and at times inability to track and contain infectious individuals compounded the situation and resulted in an as yet uncontrolled epidemic in these countries.

We estimated a mean case fatality rate of $40 \%(95 \%$ $\mathrm{Cl}$ : 22-61) for the EVD outbreak in Nigeria. This estimate based on a small sample size is at the lower end of estimates from previous outbreaks, ranging from $41 \%$ to $89 \%$ [33] and is likely a result of supportive care 
offered in dedicated facilities put in place in a timely fashion by the Nigerian authorities. In comparison, the EVD case fatality rate in the ongoing outbreak in Guinea, Sierra Leone and Liberia has been estimated at 70\% (range: 61- 89) [36]. As is the case for any emerging infection, these estimates have to be considered with caution as they are prone to many biases, including under-reporting of milder symptomatic cases (affecting the denominator) and censoring effects related to the unknown final outcome of the most recent infections.

The toll on healthcare workers in the EVD outbreak has been substantial, as they account for 11 of the 20 EVD cases in Nigeria. Past EVD outbreaks have been amplified in healthcare settings, e.g. [45,46], including in the ongoing epidemic in West Africa, with about $5 \%$ of the total number of reported EVD cases being healthcare workers based on data available as of 1 October 2014 [20,47].

Fortunately, past experience with the Zaire Ebolavirus strain also indicates that early, intense and sustained infection control measures in healthcare settings can substantially reduce the size and geographical scope of EVD outbreaks [48], which is consistent with the recent Nigerian experience.

The number of secondary cases decreased over subsequent disease generations in Nigeria, reflecting the effects of interventions, in particular the intense and rapid contact tracing strategy, the continuous surveillance of potential contacts, and the largely effective isolation of infectious individuals. Indeed, the mean reproduction number among secondary cases in Nigeria (i.e. excluding the contribution from the imported traveller) was 0.4 in the presence of control interventions. This number is below the epidemic threshold for disease spread, while a recent estimate of $\mathrm{R}$ derived from the growth rate pattern for Nigeria straddled the epidemic threshold of 1.0 [36]. In contrast, recent estimates of the reproduction number for the ongoing EVD epidemic in Sierra Leone and Liberia range between 1.5 and 2 [40-43], indicating that the outbreak is yet to be brought under control [43]. Moreover, the size of the outbreak in Nigeria is in agreement with our model simulation results when we assume that interventions were quickly instituted on day 3 of the outbreak. Our model simulations of delayed interventions, in accordance with large outbreaks in the broader West African region, demonstrate the necessity of rapid and forceful control measures. The Nigerian experience offers a critically important lesson to countries in the region not yet affected by the EVD epidemic, as well as to countries in other regions of the world that risk importation of EVD and that must remain vigilant. As a case in point, the recent importation of an EVD case in the United States from Liberia [49] proves that no country is immune to the risk of EVD in a globally connected world, but that rapid case identification and forceful interventions can stop transmission.

\section{* Addendum}

To build the EVD epidemic curve (Figure 1), we reviewed all relevant information published in Morbidity and Mortality Weekly Report [2] and WHO Ebola situational reports and updates for Nigeria published during July to September 2014 [1,5-31] and categorised the 20 reported EVD patients by reporting date and discharge status (dead/alive). To develop a detailed transmission tree for these patients (Figure 2), we built on a published tree [2], cross-referencing the information in the tree with that in the WHO reports, as well as information from local newspaper reports (e.g. [32]) that provided details on individual patient's infection links and their occupation. We categorised each patient according to the transmission setting (Ebolavirus acquired in a healthcare setting or the community), patient's geographical location (Lagos or Port Harcourt) and discharge status (dead/alive). The addendum was added on 30 April 2015, at the request of the authors, following comments from colleagues involved in the outbreak response in Nigeria.

\section{** Authors' correction}

The following corrections were made on 30 April 2015 at the request of the authors, following comments from colleagues involved in the outbreak response in Nigeria and facilitated by the editors of Eurosurveillance: the number of contacts investigated through contact tracing was changed from 898 to 894 and unnecessary information regarding contact type was removed; individual-level patient information provided in Figure 2 was removed, as was a sentence in the text providing details of a nurse who cared for the index patient, for confidentiality purposes. The reference list was expanded to include additional supporting documents and the citations were amended accordingly throughout the article. Finally, a sentence pertaining to the management of contacts that tested negative for Ebolavirus was removed in response to comments from colleagues involved in the outbreak response in Nigeria. These changes do not have any bearing on the results or conclusions of the study.

\section{Acknowledgments}

We wish to thank the Federal Ministry of Health, Abuja, Nigeria, and the staff of the Ebola Emergency Centre who coordinated the management of cases, containment of outbreaks and treatment protocols in Nigeria. We would like to acknowledge the Lundbeck Foundation and the Research And Policy for Infectious Disease Dynamics program (RAPIDD) of the United States Department of Homeland Security for sponsorship of LS; we thank Professor Iruka Okeke of Haverford College, PA, United States, for sharing some initial critical data with us. CV and GC acknowledge the financial support from the Division of International Epidemiology and Population Studies, The Fogarty International Center, United States National Institutes of Health, funded in part by the Office of Pandemics and Emerging Threats at the United States Department of Health and Human Services. GC also acknowledges support from grant NSF grant 1414374 as part of the joint NSF-NIH-USDA Ecology and Evolution of Infectious Diseases programme, United Kingdom Biotechnology and Biological Sciences Research Council grant BB/Moo8894/1 
and grant number 1318788. III: Small: Data Management for Real-Time Data Driven Epidemic simulation.

\section{Conflict of interest}

None declared.

\section{Authors' contributions}

FOF, AS, DL and OT gathered data; FOF and GC-P conducted statistical analyses and modelling; FOF, GC-P, CV, LS, OT critique the manuscript. All authors contributed to the drafting and approval of the manuscript for submission.

\section{References}

1. World Health Organization (WHO). WHO: Ebola response roadmap situation report. 1 October 2014. Geneva: WHO. [Accessed 8 Oct 2014]. Available from: http://apps.who.int/iris/bitstream/10665/135600/1/ roadmapsitrep_10ct2014_eng.pdf

2. Shuaib F, Gunnala R, Musa EO, Mahoney FJ, Oguntimehin O, Nguku PM, et al. Ebola virus disease outbreak - Nigeria, July-September 2014. MMWR Morb Mortal Wkly Rep. 2014;63(39):867-72.

3. European Centre for Disease Prevention and Control (ECDC). Outbreak of Ebola virus disease in West Africa. Third update, 1 August 2014. Stockholm: ECDC; 2014.

4. Muanya C. Nigeria: WHO, Govt shut down hospital over Ebola virus. The Guardian (Lagos). 27 Jul 2014. [Accessed 21 Sep 2014]. Available from: http://allafrica.com/ stories/201407281406.html

5. World Health Organization (WHO) Global Alert and Response. Disease outbreak news 15 July 2014: Ebola virus disease, West Africa - update. Geneva: WHO. [Accessed 5 Nov 2014]. Available from: http://www.who.int/csr/ don/2014_07_15_ebola/en/.

6. World Health Organization (WHO) Global Alert and Response. Disease outbreak news 17 July 2014: Ebola virus disease, West Africa - update. Geneva: WHO. [Accessed 5 Nov 2014]. Available from: http://www.who.int/csr/ don/2014_07_17_ebola/en/

7. World Health Organization (WHO) Global Alert and Response. Disease outbreak news 19 July 2014: Ebola virus disease, West Africa - update. Geneva: WHO. [Accessed 5 Nov 2014]. Available from: http://www.who.int/csr/ don/2014_07_19_ebola/en/

8. World Health Organization (WHO) Global Alert and Response. Disease outbreak news 24 July 2014: Ebola virus disease, West Africa - update. Geneva: WHO. [Accessed 5 Nov 2014]. Available from: http://www.who.int/csr/ don/2014_0724_ebola/en/

9. World Health Organization (WHO) Global Alert and Response. Disease outbreak news 27 July 2014: Ebola virus disease, West Africa - update. Geneva: WHO. [Accessed 5 Nov 2014]. Available from: http://www.who.int/csr/ don/2014_07_27_ebola/en/

10. World Health Organization (WHO) Global Alert and Response. Disease outbreak news 31 July 2014: Ebola virus disease, West Africa - update. Geneva: WHO. [Accessed 5 Nov 2014]. Available from: http://www.who.int/csr/ don/2014_0731 ebola/en/

11. World Health Organization (WHO) Global Alert and Response. Disease outbreak news 4 August 2014: Ebola virus disease, West Africa - update. Geneva: WHO. [Accessed 5 Nov 2014]. Available from: http://www.who.int/csr/ don/2014_08_04_ebola/en/

12. World Health Organization (WHO) Global Alert and Response. Disease outbreak news 6 August 2014: Ebola virus disease, West Africa - update. Geneva: WHO. [Accessed 5 Nov 2014]. Available from: http://www.who.int/csr/ don/2014 08_06_ebola/en/

13. World Health Organization (WHO) Global Alert and Response. Disease outbreak news 8 August 2014: Ebola virus disease, West Africa - update. Geneva: WHO. [Accessed 5 Nov 2014]. Available from: http://www.who.int/csr/ don/2014_08_08_ebola/en/

14. World Health Organization (WHO) Global Alert and Response. Disease outbreak news 11 August 2014: Ebola virus disease, West Africa - update. Geneva: WHO. [Accessed 5 Nov 2014]. Available from: http://www.who.int/csr/ don/2014_08_11_ebola/en/

15. World Health Organization (WHO) Global Alert and Response. Disease outbreak news 13 August 2014: Ebola virus disease, West Africa - update. Geneva: WHO. [Accessed 5 Nov 2014]. Available from: http://www.who.int/csr/ don/2014_08_13_ebola/en/

16. World Health Organization (WHO) Global Alert and Response. Disease outbreak news 15 August 2014: Ebola virus disease, West Africa - update. Geneva: WHO. [Accessed 5 Nov 2014]. Available from: http://www.who.int/csr/ don/2014_08_15_ebola/en/

17. World Health Organization (WHO) Global Alert and Response. Disease outbreak news 19 August 2014: Ebola virus disease, West Africa - update. Geneva: WHO. [Accessed 5 Nov 2014]. Available from: http://www.who.int/csr/ don/2014_08_19_ebola/en/

18. World Health Organization (WHO) Global Alert and Response. Disease outbreak news 20 August 2014: Ebola virus disease, West Africa - update. Geneva: WHO. [Accessed 5 Nov 2014]. Available from: http://www.who.int/csr/ don/2014_08_20_ebola/en/

19. World Health Organization (WHO) Global Alert and Response. Disease outbreak news 22 August 2014: Ebola virus disease, West Africa - update. Geneva: WHO. [Accessed 5 Nov 2014]. Available from: http://www.who.int/csr/ don/2014_08_22_ebola/en/

20. World Health Organization (WHO) Global Alert and Response. Disease outbreak news 28 August 2014: Ebola virus disease, West Africa - update. Geneva: WHO. [Accessed 5 Nov 2014]. Available from: http://www.who.int/csr/ don/2014_08_28_ebola/en/

21. World Health Organization (WHO) Global Alert and Response. Disease outbreak news 30 August 2014: Ebola virus disease, West Africa - update. Geneva: WHO. [Accessed 5 Nov 2014]. Available from: http://www.who.int/csr/ don/2014_08_30_ebola/en/

22. World Health Organization (WHO) Global Alert and Response. Disease outbreak news 1 September 2014: Ebola virus disease, West Africa - update. Geneva: WHO. [Accessed 5 Nov 2014]. Available from: http://www.who.int/csr/ don/2014_09_04_ebola/en/

23. World Health Organization (WHO). WHO: Ebola response roadmap situation report. 29 August 2014. Geneva: WHO. [Accessed 8 Oct 2014]. Available from: http://apps.who.int/ iris/bitstream/10665/131974/1/roadmapsitrep1_eng.pdf?ua=1

24. World Health Organization (WHO). WHO: Ebola response roadmap situation report. 5 September 2014. Geneva: WHO. [Accessed 8 Oct 2014]. Available from: http://apps.who.int/ iris/bitstream/10665/132687/1/roadmapsitrep2_eng.pdf?ua=1

25. World Health Organization (WHO). WHO: Ebola response roadmap situation report. 8 September 2014. Geneva: WHO. [Accessed 8 Oct 2014]. Available from: http://apps.who.int/ iris/bitstream/10665/132834/1/roadmapupdate8sept14_eng. pdf?ua=1

26. World Health Organization (WHO). WHO: Ebola response roadmap situation report. 12 September 2014. Geneva: WHO. [Accessed 8 Oct 2014]. Available from: http://apps.who.int/ iris/bitstream/10665/133073/1/roadmapsitrep3_eng.pdf?ua=1

27. World Health Organization (WHO). WHO: Ebola response roadmap situation report. 16 September 2014. Geneva: WHO. [Accessed 8 Oct 2014]. Available from: http://apps.who.int/ iris/bitstream/10665/133546/1/roadmapupdate16sept14_eng. pdf?ua $=1$

28. World Health Organization (WHO). WHO: Ebola response roadmap situation report. 18 September 2014. Geneva: WHO. [Accessed 8 Oct 2014]. Available from: http://apps.who.int/ iris/bitstream/10665/133833/1/roadmapsitrep4_eng.pdf?ua=1

29. World Health Organization (WHO). WHO: Ebola response roadmap situation report. 22 September 2014 . Geneva: WHO. [Accessed 8 Oct 2014]. Available from: http://apps.who.int/ iris/bitstream/10665/134449/1/roadmapupdate22sept14_eng. pdf?ua=1

30. World Health Organization (WHO). WHO: Ebola response roadmap situation report. 24 September 2014. Geneva: WHO. [Accessed 8 Oct 2014]. Available from: http://apps.who.int/ iris/bitstream/10665/134771/1/roadmapsitrep_24Sept2014_ eng.pdf?ua $=1$

31. World Health Organization (WHO). WHO: Ebola response roadmap situation report. 26 September 2014. Geneva: WHO. [Accessed 8 Oct 2014]. Available from: http://apps.who.int/ iris/bitstream/10665/135029/1/roadmapupdate26sept14_eng. pdf?ua $=1$

32. Through the Valley of the Shadow of Death ... Dr. Ada Igonoh survived Ebola - this is her story. Bella Naija. [Accessed 10 Sep 
2014]. Available from: http://www.bellanaija.com/2014/o9/15/ must-read-through-the-valley-of-the-shadow-of-death-dr-adaigonoh-survived-ebola-this-is-her-story/

33. Legrand J, Grais RF, Boelle PY, Valleron AJ, Flahault A. Understanding the dynamics of Ebola epidemics. Epidemiol Infect. 2007;135(4):610-21.

34. Hooker LC, Mayes C, Degeling C, Gilbert GL, Kerrigde IH. Don't be scared, be angry: the politics and ethics of Ebola. Med J Aust. 2014;201(6):352-4.

35. Eichner M, Dowell SF, Firese N. Incubation period of ebola hemorrhagic virus subtype Zaire. Osong Public Health Res Perspect. 2011;2(1):3-7.

36. WHO Ebola Response Team. Ebola virus disease in West Africa - the first 9 months of the epidemic and forward projections. $\mathrm{N}$ Engl J Med. 2014 Sep 22. [Epub ahead of print].

37. Lekone PE, Finkenstadt BF. Statistical inference in a stochastic epidemic SEIR model with control intervention: Ebola as a case study. Biometrics. 2006;62(4):1170-7.

38. Chowell G, Hengartner NW, Castillo-Chavez C, Fenimore PW, Hyman JM. The basic reproductive number of Ebola and the effects of public health measures: the cases of Congo and Uganda. J Theor Biol. 2004; 229(1):119-26.

39. Diekmann O, Heesterbeek JA. Mathematical epidemiology of infectious diseases: model building, analysis and interpretation. San Francisco, CA: Wiley; 2000.

40. Althaus CL. Estimating the reproduction number of Zaire ebolavirus (EBOV) during the 2014 outbreak in West Africa. PLOS Currents Outbreaks. 2014. Edition 1. doi: 10.1371/ currents.outbreaks.91afb5eof279e7f29e7056095255b288.

41. Fisman D, Khoo E, Tuite A. Early epidemic dynamics of the West African 2014 Ebola outbreak: estimates derived with a simple two-parameter model. PLOS Currents Outbreaks. 2014. Edition 1. doi: $10.1371 /$ currents.outbreaks.89cod3783f36958d96ebba e97348d571.

42. Gomes MF, Pastore y Piontti A, Rossi L, Chao D, Longini I, Halloran ME, et al. Assessing the international spreading risk associated with the 2014 West African Ebola outbreak. PLOS Currents Outbreaks. 2014. Edition 1. doi: 10.1371/currents. outbreaks.cd818f63d40e24aef769dda7df9eoda5.

43. Nishiura $\mathrm{H}$, Chowell G. Early transmission dynamics of Ebola virus disease (EVD), West Africa, March to August 2014. Euro Surveill. 2014;19(36): pii=20894.

44. Baize S, Pannetier D, Oestereich L, Rieger T, Koivogui L, Magassouba N, et al. Emergence of Zaire Ebola virus disease in Guinea - preliminary report. N Engl J Med. 2014;371(15):141825. Epub 2014 Apr 16.

45. Baron RC, McCormick JB, Zubeir OA. Ebola virus disease in southern Sudan: hospital dissemination and intrafamilial spread. Bull World Health Organ. 1983;61(6):997-1003.

46. Khan AS, Tshioko FK, Heymann DL, Le Guenno B, Nabeth P, Kerstiëns B, et al. The reemergence of Ebola hemorrhagic fever, Democratic Republic of the Congo, 1995. Commission de Lutte contre les Epidemies a Kikwit. J Infect Dis. 1999;179 Suppl 1:S76-86.

47. World Health Organization (WHO). Unprecedented number of medical staff infected with Ebola. Situation assessment - 25 August 2014. Geneva: WHO. [Accessed 4 Oct 2014]. Available from: http://www.who.int/mediacentre/news/ ebola/25-august-2014/en/

48. Nkoghe D, Kone ML, Yada A, Leroy E. A limited outbreak of Ebola haemorrhagic fever in Etoumbi, Republic of Congo, 2005. Trans R Soc Trop Med Hyg. 2011;105(8):466-72.

49. Centers for Disease Control and Prevention (CDC). CDC update on first Ebola case diagnosed in the United States: 10-082014. Atlanta, GA: CDC. [Accessed 8 Oct 2014]. Available from: http://www.cdc.gov/media/releases/2014/a1007-ebolaconfirmed-case.html 